\title{
Thermophysical Properties of Solutions of Iron(III) Nitrate Nonahydrate in Mixtures of 1-Propanol and Water
}

\author{
Alexander Keller ${ }^{1}$, Irenäus Wlokas ${ }^{2}$, Maximilian Kohns*,1, Hans Hasse ${ }^{1}$ \\ ${ }^{1}$ University of Kaiserslautern, Laboratory of Engineering Thermodynamics, \\ Erwin-Schrödinger-Str. 44, D-67663 Kaiserslautern, Germany \\ ${ }^{2}$ University Duisburg-Essen, Fluid Dynamics, Institute for Combustion and Gas Dynamics, Carl- \\ Benz-Str. 199, D-47057 Duisburg, Germany
}

\begin{abstract}
The simulation of spray flame processes for the production of high quality nanoparticles relies on thermophysical properties of the precursor solutions, for which literature data are scarce. Here, we report experimental thermophysical data of solutions of iron(III) nitrate nonahydrate (INN) in (1-propanol + water) mixed solvents. The specific density, viscosity, thermal conductivity and isobaric heat capacity of the solutions were measured at $101.3 \mathrm{kPa}$ between 288.15 and $333.15 \mathrm{~K}$, solvent compositions ranging from $0.73 \mathrm{~mol} \mathrm{~mol}^{-1} 1$-propanol to pure water, and INN molalities up to $1.3 \mathrm{~mol} \mathrm{\textrm {kg } ^ { - 1 }}$. Empirical correlations of the experimental data are provided.
\end{abstract}

Keywords: Thermophysical Properties, Thermal conductivity, Heat capacity, Spray Flame Synthesis, Nanoparticles

*Corresponding author; maximilian.kohns@mv.uni-kl.de 


\section{Introduction}

Solutions of iron(III) nitrate nonahydrate (INN) in primary alcohols are used as precursor solutions for the production of iron oxide nanoparticles with spray flame synthesis processes ${ }^{1-6}$. For a better understanding of these processes, simulations are performed for which thermophysical data on the precursor solutions are needed ${ }^{7-9}$. However, such data are scarce in the literature. Recently, a standardized synthesis setup was suggested by the SpraySyn initiative ${ }^{3}$, which further motivates the investigation of thermophysical properties of precursor solutions for the production of iron oxide ${ }^{10}$ or titania ${ }^{11}$ nanoparticles. As a part of this initiative, we recently reported experimental data on thermophysical properties of solutions of INN in mixtures of ethanol and water ${ }^{10}$. Consequently, as the next primary alcohol in the homologous series, solutions with 1-propanol are investigated here, which are also of interest for spray flame synthesis ${ }^{6}$. To the best of our knowledge, no information on the thermophysical properties of these solutions is available in the literature, except for the specific density of aqueous INN solutions ${ }^{12}$, which is already discussed in our $\operatorname{previous~work~}^{10}$.

In contrast, plenty of data have been reported for mixtures of 1-propanol and water (without INN). Many authors have measured their density ${ }^{13-19}$. A negative molar excess volume is found, which is caused by the structuring of alcohol + water mixtures due to H-bonding. Data on the viscosity of mixtures of 1-propanol and water have been reported by several authors ${ }^{17,18,20-26}$. The mixture viscosities are higher than it would be the case for ideal mixtures, which is as well caused by H-bonding. The thermal conductivity of mixtures of 1-propanol and water was measured by Assael et al. ${ }^{27}$. Similar to mixtures of other primary alcohols and water, the thermal 
conductivity of 1-propanol increases with decreasing temperature, whereas for pure water the opposite trend is observed. As a result, mixture compositions can be found for which the thermal conductivity is independent of the temperature. To the best of our knowledge, no data on the isobaric heat capacity of mixtures of 1-propanol and water are available in the literature.

To summarize: except for the isobaric heat capacity, thermophysical properties of mixtures of 1-propanol and water are known. By contrast, for solutions of INN in these solvents, the density of aqueous INN solutions is the only property for which data are available in the literature. Accordingly, in the present work, the specific density, viscosity, thermal conductivity and molar isobaric heat capacity of solutions of INN in mixtures of 1-propanol and water were measured at temperatures ranging from 288.15 to $333.15 \mathrm{~K}$ and at ambient pressure, with solvent compositions between $0.73 \mathrm{~mol} \mathrm{~mol}^{-1}$ 1-propanol and pure water and overall INN molalities up to $1.3 \mathrm{~mol} \mathrm{~kg} \mathrm{k}^{-1}$. Correlations of the data are provided, which e.g. enable the use of the thermophysical data in numerical simulations.

For the sake of brevity, we write "density" for "specific density" and "isobaric heat capacity" for "molar isobaric heat capacity". The specified standard uncertainties for all measurements include statistical and method uncertainties.

\section{Experimental}

\subsection{Chemicals and sample preparation}

Information on the used chemicals, such as CAS registry number, supplier and purity, is provided in Table 1.

[Table 1 about here.] 
Aqueous solutions were prepared with water from a Milli-Q® System (Millipore) with a specific electrical resistance greater than $18.2 \mathrm{M} \Omega \mathrm{cm}$. To prevent INN oxidation in air, it was handled in a nitrogen glove box (GS Glovebox Technik), where the water content was below $2 \cdot 10^{-6} \mathrm{~g} \mathrm{~g}^{-1}$ and the oxygen content below $1.2 \cdot 10^{-6} \mathrm{~g} \mathrm{~g} \mathrm{~g}^{-1}$. For the sample preparation, a laboratory balance (Mettler-Toledo AG204) with a standard uncertainty of $\pm 0.0001 \mathrm{~g}$ was used.

It was found that INN is practically insoluble in pure 1-propanol. The same holds for (1-propanol + water) mixed solvents containing more than $0.73 \mathrm{~mol} \mathrm{~mol}^{-1}$ 1-propanol (corresponding to $0.90 \mathrm{~g} \mathrm{~g}^{-1} 1$-propanol). Thus, we report only data for INN in mixed solvents with 1-propanol concentrations below this limit.

\subsection{Measurements}

All measurements were performed at $p=101.3 \pm 3 \mathrm{kPa}$. Following our previous work $^{10}$, the mixtures are considered as ternary systems comprising the components INN $\left(\mathrm{Fe}\left(\mathrm{NO}_{3}\right)_{3} \cdot 9 \mathrm{H}_{2} \mathrm{O}\right)$, 1-propanol and water, i.e. the overall composition of the solution is reported, where the iron nitrate crystal water does not add up to the solvent water. Salt-free properties are denoted by a circumflex $\left({ }^{\wedge}\right)$. The composition of the ternary mixtures is specified by the overall molality of INN $b_{\mathrm{INN}}$ and the mole fraction of 1-propanol (P) in the salt-free solvent mixture $\hat{x}_{\mathrm{P}}$,

$$
\begin{aligned}
& b_{\mathrm{INN}}=\frac{n_{\mathrm{INN}}}{\hat{m}_{\mathrm{Solv}}}, \\
& \hat{m}_{\mathrm{Solv}}=n_{\mathrm{P}} \cdot M_{\mathrm{P}}+n_{\mathrm{W}} \cdot M_{\mathrm{W}}, \\
& \hat{x}_{\mathrm{P}}=\frac{n_{\mathrm{P}}}{n_{\mathrm{P}}+n_{\mathrm{W}}},
\end{aligned}
$$

where $n_{\mathrm{P}}$ and $n_{\mathrm{W}}$ are the numbers of moles of the solvents 1-propanol and water (W) on a salt-free basis, and $n_{\mathrm{INN}}$ is the number of moles of INN. 
In the experiments carried out in the present work, the solvent composition varied between $0 \leq \hat{x}_{\mathrm{P}} \leq 0.73 \mathrm{~mol} \mathrm{~mol}^{-1}$. The overall INN molality varied between $0 \leq b_{\mathrm{INN}} \leq 1.3 \mathrm{~mol} \mathrm{~kg}^{-1}$. The standard uncertainty of $\hat{x}_{\mathrm{P}}$ is below $\pm 0.0005 \mathrm{~mol} \mathrm{~mol}^{-1}$ and the standard uncertainty of $b_{\mathrm{INN}}$ is below $\pm 0.005 \mathrm{~mol} \mathrm{~kg}^{-1}$. Samples were hermetically sealed in $40 \mathrm{~mL}$ glass vials. The measurements were performed within $1 \mathrm{~h}$ after sample preparation.

\subsubsection{Density and viscosity}

As in our previous work ${ }^{10}$, the density and viscosity were measured with an instrument of Anton Paar (SVM 3000) at 293.15 to $333.15 \mathrm{~K}$. The (relative) standard uncertainties are $u_{\mathrm{r}}(\rho)=0.002, u_{\mathrm{r}}(\eta)=0.03$ (for high mole fractions of 1-propanol in the mixed solvent) to $u_{\mathrm{r}}(\eta)=0.07$ (for pure water as the solvent) and $u(T)=0.05 \mathrm{~K}$. For validation, the density and viscosity of pure 1-propanol and mixtures of 1propanol and water were measured and compared to literature values of several authors. The results are presented in the Supporting Information. The relative deviations $d_{\mathrm{r}}$ between the reported density data and our own measurements were found to be $d_{\mathrm{r}}(\rho) \leq 0.0016$. Relative deviations between the reported viscosity data were found to be $d_{\mathrm{r}}(\eta) \leq 0.03$ in all cases.

\subsubsection{Thermal conductivity and isobaric heat capacity}

As in our previous work ${ }^{10}$, the thermal conductivity and the isobaric heat capacity were measured using an instrument of flucon fluid control GmbH (LAMBDA) at $288.15,298.15$ and $308.15 \mathrm{~K}$. The (relative) standard uncertainties are $u_{\mathrm{r}}(\lambda)=0.035$, $u_{\mathrm{r}}\left(c_{\mathrm{p}}\right)=0.04$ and $u(T)=0.2 \mathrm{~K}$. The apparatus was calibrated to the thermal conductivity and isobaric heat capacity of the pure solvents at $298.15 \mathrm{~K}$. For validation, the thermal conductivity of mixtures of 1-propanol and water and the 
isobaric heat capacity of 1-propanol at temperatures other than $298.15 \mathrm{~K}$ were measured and compared to literature values of several authors. The results are presented in the Supporting Information. The relative deviations between the reported thermal conductivity data and our own measurements were found to be $d_{\mathrm{r}}(\lambda) \leq 0.01$ for pure 1-propanol and below $d_{\mathrm{r}}(\lambda) \leq 0.035$ for mixtures of 1-propanol and water. The relative deviations between the reported isobaric heat capacity data were found to be below $d_{\mathrm{r}}\left(c_{\mathrm{p}}\right) \leq 0.04$ for pure 1-propanol.

\section{Modeling}

All properties are correlated with simple polynomials in composition and temperature as described in our previous work ${ }^{10}$. We briefly repeat the correlations here for convenience. The molar volume of a mixture is correlated as

$$
v=\hat{x}_{\mathrm{P}} v_{\mathrm{P}}^{\text {pure }}+\hat{x}_{\mathrm{W}} v_{\mathrm{W}}^{\mathrm{pure}}+v_{\mathrm{Solv}}^{\mathrm{E}}+\xi
$$

where $v_{\mathrm{P}}^{\text {pure }}$ and $v_{\mathrm{W}}^{\text {pure }}$ are the temperature-dependent pure component molar volumes of 1-propanol and water

$$
v^{\text {pure }} / \mathrm{cm}^{3} \mathrm{~mol}^{-1}=a+b \cdot(T / \mathrm{K})+c \cdot(T / \mathrm{K})^{2},
$$

where $a, b$ and $c$ are adjustable parameters.

The excess molar volume $v_{\text {Solv }}^{\mathrm{E}}$ of the solvent mixture is correlated using a Redlich-Kister polynomial

$$
\begin{aligned}
\frac{v_{\mathrm{Solv}}^{\mathrm{E}}}{\mathrm{cm}^{3} \mathrm{~mol}^{-1}} & =A \cdot \hat{x}_{\mathrm{P}} \hat{x}_{\mathrm{W}} \\
& +B \cdot \hat{x}_{\mathrm{P}} \hat{x}_{\mathrm{W}} \cdot\left(\hat{x}_{\mathrm{P}}-\hat{x}_{\mathrm{W}}\right) \\
& +C \cdot \hat{x}_{\mathrm{P}} \hat{x}_{\mathrm{W}} \cdot\left(\hat{x}_{\mathrm{P}}-\hat{x}_{\mathrm{W}}\right)^{2}
\end{aligned}
$$

where $A, B$ and $C$ are temperature-dependent adjustable parameters, which are correlated with 


$$
A=d+e \cdot(T / \mathrm{K})+f \cdot(T / \mathrm{K})^{2} .
$$

$\xi$ describes the influence of INN on the molar volume as

$$
\begin{aligned}
\xi / \mathrm{cm}^{3} \mathrm{~mol}^{-1}= & x_{\mathrm{INN}} \cdot\left(D+E \cdot \hat{x}_{\mathrm{P}}+F \cdot \hat{x}_{\mathrm{P}}^{2}+G \cdot \hat{x}_{\mathrm{P}}^{3}\right) \\
& +x_{\mathrm{INN}}^{2} \cdot\left(H+I \cdot \hat{x}_{\mathrm{P}}+J \cdot \hat{x}_{\mathrm{P}}^{2}+K \cdot \hat{x}_{\mathrm{P}}^{3}\right)
\end{aligned} .
$$

Here, $x_{\mathrm{INN}}$ is the mole fraction of INN in the mixture, and $D, E, F, G, H, I, J$ and $K$ are temperature-dependent adjustable parameters, which are correlated with

$$
D=g+h \cdot(T / \mathrm{K})
$$

The overall mole fraction of INN in the mixture $x_{\mathrm{INN}}$ is defined as

$$
x_{\mathrm{INN}}=\frac{n_{\mathrm{INN}}}{n_{\mathrm{INN}}+n_{\mathrm{P}}+n_{\mathrm{W}}},
$$

where $n_{\mathrm{INN}}, n_{\mathrm{P}}$ and $n_{\mathrm{W}}$ are the mole numbers of INN, 1-propanol and water, respectively. Inserting Eq. (10) in Eq. (1) and rearranging leads to the conversion of $b_{\text {INN }}$ to $x_{\text {INN }}$ as follows

$$
x_{\mathrm{INN}}=\frac{b_{\mathrm{INN}}}{b_{\mathrm{INN}}+\frac{1}{\bar{M}_{\mathrm{Solv}}}} \text {. }
$$

Here, $\bar{M}_{\text {Solv }}$ denotes the mean molar mass of the solvent on a salt-free basis.

The other properties, i.e. the viscosity $\eta$ (in units $\mathrm{mPa} s$ ), thermal conductivity $\lambda$ (in units $\mathrm{mW} \mathrm{m}^{-1} \mathrm{~K}^{-1}$ ) and isobaric heat capacity $c_{\mathrm{p}}$ (in units $\mathrm{J} \mathrm{mol}^{-1} \mathrm{~K}^{-1}$ ) are correlated according to the molar volume, i.e. using Eqs. (1) - (11).

In most cases, not all of the adjustable parameters in Eqs. (5) - (9) are used. Only those parameters required for obtaining a satisfactory fit of the data were included to allow for meaningful extrapolations of the correlations.

The fitting of the correlation parameters is performed as described in our previous work ${ }^{10}$ by the MATLAB ${ }^{28}$ solver "Isqnonlin". The quality of the fits is assessed for 
either of the properties $z$ by evaluating the average absolute relative deviation (AARD)

$$
\mathrm{AARD}=\frac{1}{N_{\mathrm{p}}} \sum_{i=1}^{N_{\mathrm{p}}}\left|\frac{z_{i}^{\exp }-z_{i}^{\mathrm{cal}}}{z_{i}^{\exp }}\right|,
$$

where $N_{\mathrm{p}}$ is the number of experimental points and the superscripts "exp" and “cal" denote experimental and calculated results.

\section{Results and discussion}

In the following sections, results for the different properties of mixtures of INN, 1propanol and water are presented in Tables $2-5$ and Figures $1-4$ as functions of $\hat{x}_{\mathrm{P}}$ (cf. Eq. (3)), $b_{\mathrm{INN}}$ (cf. Eq. (1)) and the temperature $T$. The correlation parameters fit to the experimental data by means of Eqs. (5) - (9) are provided in Tables $6-8$. Results for the thermal diffusivity $a$, as well as results for the different properties as functions of the true mole numbers are shown in the Supporting Information.

\subsection{Density}

The experimental densities of mixtures of INN, 1-propanol and water, as well as the density correlation are shown in Figure 1.

[Figure 1 about here.]

With decreasing temperature and increasing molality of INN the density increases. At $\hat{x}_{\mathrm{P}}=0.73 \mathrm{~mol} \mathrm{~mol}^{-1}, b_{\mathrm{INN}}=0.248 \mathrm{~mol} \mathrm{~kg}^{-1}$ and $T=333.15 \mathrm{~K}$ a solid precipitated from the mixture during the measurement, which is why the data point was discarded. The correlation describes the experimental data mostly within the experimental standard uncertainty except for some INN molalities at $\hat{x}_{\mathrm{P}}=0.73 \mathrm{~mol} \mathrm{~mol}^{-1}$, where the relative deviation between experimental data and the correlation is little higher, but is always below $d_{\mathrm{r}}(\rho) \leq 0.005$. The AARD of the experimental density data to the 
density correlation is 0.002 , which is equal to the uncertainty of the experimental density data.

\subsection{Viscosity}

The experimental viscosities of mixtures of INN, 1-propanol and water, as well as the viscosity correlation are shown in Figure 2.

[Figure 2 about here.]

With decreasing temperature and with increasing molality of INN the viscosity increases. At $\hat{x}_{\mathrm{P}}=0.73 \mathrm{~mol} \mathrm{~mol}^{-1}, b_{\mathrm{INN}}=0.248 \mathrm{~mol} \mathrm{~kg}^{-1}$ and $T=333.15 \mathrm{~K}$ a solid precipitated from the mixture during the measurement, which is why the data point was discarded. The correlation describes the experimental data mostly within the experimental standard uncertainty, except for high INN molalities and low temperatures, where the slope of the viscosity is steep. The AARD of the experimental viscosity data to the viscosity correlation is 0.039 , which is lower than the uncertainty of the experimental viscosity data.

\subsection{Thermal conductivity}

The experimental thermal conductivities of mixtures of INN, 1-propanol and water, as well as the thermal conductivity correlation are shown in Figure 3.

[Figure 3 about here.]

As in systems with ethano ${ }^{10}$, the behavior of the thermal conductivity of mixtures of INN, 1-propanol and water is much more complex than that of the other properties. For pure water as the solvent, the thermal conductivity first decreases with increasing molality of INN, shows a minimum at about $b_{\mathrm{INN}}=0.6 \mathrm{~mol} \mathrm{~kg}{ }^{-1}$, and increases upon further addition of INN. A similar behavior is observed for the mixed solvent with high 1-propanol content. By contrast, for the mixed solvent with $\hat{x}_{\mathrm{P}}=0.23 \mathrm{~mol} \mathrm{~mol}^{-1}$, 
no distinct minimum is found, except for a very shallow one at the lowest temperature. The temperature dependence shows a simpler trend: The thermal conductivity is high for high temperatures. The only exception are solvent mixtures with $\hat{x}_{\mathrm{P}}=0.73 \mathrm{~mol} \mathrm{~mol}^{-1}$ and low INN molalities, for which the temperature dependence is reversed. As a consequence, at about $b_{\mathrm{INN}}=0.07 \mathrm{~mol} \mathrm{~kg}^{-1}$ a mixture composition is found for which the thermal conductivity does not depend on temperature. This complex behavior is very likely caused by the fact that water and 1propanol show an opposite temperature dependence of the thermal conductivity. The AARD of the experimental thermal conductivity data to the thermal conductivity correlation is 0.02 , which is lower than the uncertainty of the experimental thermal conductivity data.

\subsection{Isobaric heat capacity}

The experimental isobaric heat capacities of mixtures of INN, 1-propanol and water, as well as the isobaric heat capacity correlation are shown in Figure 4.

[Figure 4 about here.]

With increasing molality of INN and increasing temperature the isobaric heat capacity first decreases, then increases. The correlation describes the experimental data within the experimental standard uncertainty. The AARD of the experimental isobaric heat capacity data to the heat capacity correlation is 0.022 , which is lower than the uncertainty of the experimental isobaric heat capacity data.

\section{Conclusions}

In the present work, thermophysical properties of mixtures of iron(III) nitrate nonahydrate (INN), 1-propanol and water, which are used in the spray flame 
synthesis of iron oxide nanoparticles were measured and correlated empirically. The properties are density, viscosity, thermal conductivity and isobaric heat capacity. In general, the properties follow the same overall trends as observed in our previous work on solutions of INN in ethanol and water. The knowledge of these properties establishes a solid basis for simulations of the spray flame synthesis of nanoparticles. Thereby, with the present data set contributes to a better understanding of the droplet evaporation process and the atomization of the precursor solution.

\section{Acknowledgements}

This work was supported by the German Research Foundation (DFG) within the priority program SPP 1980 SPRAYSYN under grant HA 1993/18-1.

\section{Associated content}

Supporting Information Available: Comparison of experimental data for pure 1propanol and mixtures of 1-propanol and water to literature data; results for the thermal diffusivity; experimental results as functions of true mole fractions.

\section{References}

(1) Strobel, R.; Pratsinis, S. E. Direct Synthesis of Maghemite, Magnetite and Wustite Nanoparticles by Flame Spray Pyrolysis. Adv. Powder Technol. 2009, 20, 190-194.

(2) Dosev, D.; Nichkova, M.; Dumas, R. K.; Gee, S. J.; Hammock, B. D.; Liu, K.; Kennedy, I. M. Magnetic/Luminescent Core/Shell Particles Synthesized by 
Spray Pyrolysis and Their Application in Immunoassays with Internal Standard. Nanotechnology 2007, 18, 055102.

(3) Schneider, F.; Suleiman, S.; Menser, J.; Borukhovich, E.; Wlokas, I.; Kempf, A.; Wiggers, H.; Schulz, C. SpraySyn-A Standardized Burner Configuration for Nanoparticle Synthesis in Spray Flames. Rev. Sci. Instrum. 2019, 90, 085108.

(4) Rosebrock, C. D.; Wriedt, T.; Mädler, L.; Wegner, K. The Role of Microexplosions in Flame Spray Synthesis for Homogeneous Nanopowders from Low-Cost Metal Precursors. AIChE J. 2016, 62, 381-391.

(5) Strobel, R.; E. Pratsinis, S. Effect of Solvent Composition on Oxide Morphology during Flame Spray Pyrolysis of Metal Nitrates. Phys. Chem. Chem. Phys. 2011, 13, 9246-9252.

(6) Stodt, M. F. B.; Gonchikzhapov, M.; Kasper, T.; Fritsching, U.; Kiefer, J. Chemistry of Iron Nitrate-Based Precursor Solutions for Spray-Flame Synthesis. Phys. Chem. Chem. Phys. 2019, 21, 24793-24801.

(7) Sirignano, W. A. Fluid Dynamics and Transport of Droplets and Sprays; Cambridge University Press, 1999.

(8) Rittler, A.; Deng, L.; Wlokas, I.; Kempf, A. M. Large Eddy Simulations of Nanoparticle Synthesis from Flame Spray Pyrolysis. Proc. Combust. Inst. 2017, $36,1077-1087$.

(9) Abramzon, B.; Sirignano, W. A. Droplet Vaporization Model for Spray Combustion Calculations. Int. J. Heat Mass Transf. 1989, 32, 1605-1618. 
(10) Keller, A.; Wlokas, I.; Kohns, M.; Hasse, H. Thermophysical Properties of Solutions of Iron(III) Nitrate-Nonahydrate in Mixtures of Ethanol and Water. $J$. Chem. Eng. Data 2020.

(11) Keller, A.; Wlokas, I.; Kohns, M.; Hasse, H. Thermophysical Properties of Mixtures of Titanium(IV) Isopropoxide (TTIP) and p-Xylene. J. Chem. Eng. Data 2020, 65, 869-876.

(12) Arrad, M.; Kaddami, M.; Sippola, H.; Taskinen, P. Thermodynamic Modeling of Apparent Molal Volumes of Metal Nitrate Salts with Pitzer Model. J. Chem. Eng. Data 2015, 60, 856-859.

(13) Zarei, H. A.; Shahvarpour, S. Volumetric Properties of Binary and Ternary Liquid Mixtures of 1-Propanol (1)+ 2-Propanol (2)+ Water (3) at Different Temperatures and Ambient Pressure (81.5 KPa). J. Chem. Eng. Data 2008, 53, $1660-1668$.

(14) Johnson, I.; Costa, H. F.; Ferreira, A. G. M.; Fonseca, I. M. A. Density, Viscosity, and Surface and Interfacial Tensions of Mixtures of Water+ n-Butyl Acetate+ 1-Propanol at $303.15 \mathrm{~K}$ and Atmospheric Pressure. Int. J. Thermophys. 2008, 29, 619-633.

(15) Shalmashi, A.; Amani, F. Densities and Excess Molar Volumes for Binary Solution of Water + Ethanol, + Methanol and + Propanol from (283.15 to 313.15) K. Lat. Am. Appl. Res. 2014, 44, 163-166.

(16) Watson, G.; Lafitte, T.; Zéberg-Mikkelsen, C. K.; Baylaucq, A.; Bessieres, D.; Boned, C. Volumetric and Derivative Properties under Pressure for the System 1-Propanol+ Toluene: A Discussion of PC-SAFT and SAFT-VR. Fluid Phase Equilib. 2006, 247, 121-134. 
(17) Kermanpour, F.; Niakan, H. Z.; Sharifi, T. Density and Viscosity Measurements of Binary Alkanol Mixtures from (293.15 to 333.15) K at Atmospheric Pressure. J. Chem. Eng. Data 2013, 58, 1086-1091.

(18) Zhu, C.; Han, S.; Liu, J.; Ma, Y. Densities and Viscosities of Diaminotoluene with Water, Ethanol, Propan-1-O1, and Butan-1-O1 from (293.15 to 333.15) K. J. Chem. Eng. Data 2014, 59, 880-889.

(19) Ramos-Estrada, M.; López-Cortés, I. Y.; Iglesias-Silva, G. A.; PérezVillaseñor, F. Density, Viscosity, and Speed of Sound of Pure and Binary Mixtures of Ionic Liquids Based on Sulfonium and Imidazolium Cations and Bis (Trifluoromethylsulfonyl) Imide Anion with 1-Propanol. J. Chem. Eng. Data 2018, 63, 4425-4444.

(20) Assael, M. J.; Polimatidou, S. K. Measurements of the Viscosity of Alcohols in the Temperature Range $290-340 \mathrm{~K}$ at Pressures up to $30 \mathrm{MPa}$. Int. J. Thermophys. 1994, 15, 95-107.

(21) Aminabhavi, T. M.; Gopalakrishna, B. Densities, Viscosities, and Refractive Indices of Bis (2-Methoxyethyl) Ether+ Cyclohexane Or+ 1, 2, 3, 4Tetrahydronaphthalene and of 2-Ethoxyethanol+ Propan-1-O1,+ Propan-2-O1, Or+ Butan-1-Ol. J. Chem. Eng. Data 1995, 40, 462-467.

(22) Romano, E.; Trenzado, J. L.; González, E.; Matos, J. S.; Segade, L.; Jiménez, E. Thermophysical Properties of Four Binary Dimethyl Carbonate + 1-Alcohol Systems at 288.15-313.15 K. Fluid Phase Equilib. 2003, 211, 219-240.

(23) González, B.; Calvar, N.; Domínguez, Á.; Tojo, J. Dynamic Viscosities of Binary Mixtures of Cycloalkanes with Primary Alcohols at $\mathrm{T}=(293.15$, 
298.15, and 303.15) K: New UNIFAC-VISCO Interaction Parameters. J. Chem. Thermodyn. 2007, 39, 322-334.

(24) Bhuiyan, M. M. H.; Ferdaush, J.; Uddin, M. H. Densities and Viscosities of Binary Mixtures of $\$\{\$$ dimethylsulfoxide+ Aliphatic Lower Alkanols (C1C3) $\$ \$$ at Temperatures from $\mathrm{T}=303.15 \mathrm{~K}$ to $\mathrm{T}=323.15 \mathrm{~K}$. J. Chem. Thermodyn. 2007, 39, 675-683.

(25) Costa, H. F.; Lourenço, H.; Johnson, I.; Gonçalves, F. A.; Ferreira, A. G.; Fonseca, I. M. Liquid- Liquid Equilibria, Density, Viscosity, and Surface and Interfacial Tension of the System Water+ n-Butyl Acetate+ 1-Propanol at 323.15 K and Atmospheric Pressure. J. Chem. Eng. Data 2009, 54, 2845-2854.

(26) Weber, W. Über die Druckabhängigkeit der Viskosität von Alkohol-WasserGemischen. Rheol. Acta 1975, 14, 1012-1025.

(27) Assael, M. J.; Charitidou, E.; Wakeham, W. A. Absolute Measurements of the Thermal Conductivity of Mixtures of Alcohols with Water. Int. J. Thermophys. 1989, 10, 793-803.

(28) MATLAB R2014b; The Mathworks, Inc.: Natick, Massachusetts, US.

(29) Abu-Daabes, M. A.; Awwad, A. M. Volumetric and Viscometric Properties of Aqueous Solutions of N-(2-Hydroxyethyl)Morpholine at $\mathrm{T}=(293.15,303.15$, 313.15, 323.15, 333.15) K. J. Chem. Thermodyn. 2008, 40, 874-878. 
Table 1: Chemical specification.

\begin{tabular}{l|cccc}
\hline \hline & CAS reg. no. & supplier & Purity & analysis method \\
\hline $\mathrm{Fe}\left(\mathrm{NO}_{3}\right)_{3} \cdot 9 \mathrm{H}_{2} \mathrm{O}$ & $7782-61-8$ & Sigma Aldrich & $0.9995 \mathrm{~g} \mathrm{~g}^{-1}$ & as stated by supplier \\
$n-\mathrm{C}_{3} \mathrm{H}_{7} \mathrm{OH}$ & $71-23-8$ & Sigma Aldrich & $0.9999 \mathrm{~g} \mathrm{~g}^{-1}$ & ${ }^{1} \mathrm{H}-\mathrm{NMR}$ spectroscopy \\
& & & & \\
\hline \hline
\end{tabular}


Table 2: Results of the density measurements: 1-propanol mole fraction of the INN-free solvent mixture $\hat{x}_{\mathrm{P}}$, overall INN molality $b_{\mathrm{INN}}$, temperature $T$, density $\rho$. The pressure $p$ is $101.3 \mathrm{kPa}$. The standard uncertainties are $u\left(\hat{x}_{\mathrm{P}}\right)=0.0005 \mathrm{~mol} \mathrm{~mol}^{-1}$, $u\left(b_{\mathrm{INN}}\right)=0.005 \mathrm{~mol} \mathrm{~kg}^{-1}, u(T)=0.05 \mathrm{~K}, u_{\mathrm{r}}(\rho)=0.002$ and $u(p)=3 \mathrm{kPa}$. Data for pure water as the solvent from our previous work $^{10}$ (rounded to match the number of decimals) are included here for convenience.

\begin{tabular}{|c|c|c|c|c|c|c|c|}
\hline \multirow{2}{*}{$\begin{array}{c}\hat{x}_{\mathrm{P}} \\
\mathrm{mol} \mathrm{mol}^{-1}\end{array}$} & \multirow{2}{*}{$\begin{array}{c}b_{\mathrm{INN}} \\
\mathrm{mol} \mathrm{kg}^{-1}\end{array}$} & \multicolumn{5}{|c|}{$\rho / \mathrm{g} \mathrm{cm}^{-3}$} & \\
\hline & & $T=293.15 \mathrm{~K}$ & $303.15 \mathrm{~K}$ & $313.15 \mathrm{~K}$ & $323.15 \mathrm{~K}$ & $333.15 \mathrm{~K}$ & \\
\hline \multirow[t]{6}{*}{0} & 0 & 0.998 & 0.996 & 0.992 & 0.988 & 0.983 & \multirow{6}{*}{10} \\
\hline & 0.248 & 1.041 & 1.038 & 1.034 & 1.030 & 1.024 & \\
\hline & 0.495 & 1.080 & 1.076 & 1.072 & 1.067 & 1.062 & \\
\hline & 0.743 & 1.115 & 1.111 & 1.106 & 1.101 & 1.096 & \\
\hline & 0.990 & 1.146 & 1.142 & 1.137 & 1.131 & 1.125 & \\
\hline & 1.237 & 1.175 & 1.170 & 1.165 & 1.159 & 1.153 & \\
\hline \multirow[t]{6}{*}{0.0908} & 0 & 0.961 & 0.954 & 0.948 & 0.941 & 0.934 & \multirow{24}{*}{ this work } \\
\hline & 0.246 & 1.003 & 0.997 & 0.990 & 0.983 & 0.976 & \\
\hline & 0.493 & 1.041 & 1.035 & 1.028 & 1.021 & 1.014 & \\
\hline & 0.739 & 1.075 & 1.068 & 1.062 & 1.055 & 1.048 & \\
\hline & 0.954 & 1.106 & 1.100 & 1.093 & 1.086 & 1.079 & \\
\hline & 1.231 & 1.134 & 1.128 & 1.121 & 1.114 & 1.106 & \\
\hline \multirow[t]{6}{*}{0.2306} & 0 & 0.910 & 0.902 & 0.894 & 0.886 & 0.878 & \\
\hline & 0.246 & 0.952 & 0.945 & 0.937 & 0.929 & 0.921 & \\
\hline & 0.499 & 0.992 & 0.984 & 0.976 & 0.968 & 0.960 & \\
\hline & 0.740 & 1.026 & 1.018 & 1.011 & 1.003 & 0.995 & \\
\hline & 0.982 & 1.057 & 1.050 & 1.042 & 1.034 & 1.025 & \\
\hline & 1.231 & 1.087 & 1.079 & 1.071 & 1.063 & 1.055 & \\
\hline \multirow[t]{6}{*}{0.4734} & 0 & 0.858 & 0.850 & 0.841 & 0.833 & 0.824 & \\
\hline & 0.247 & 0.902 & 0.894 & 0.885 & 0.877 & 0.868 & \\
\hline & 0.493 & 0.942 & 0.934 & 0.925 & 0.916 & 0.907 & \\
\hline & 0.738 & 0.978 & 0.969 & 0.961 & 0.952 & 0.943 & \\
\hline & 0.986 & 1.010 & 1.002 & 0.993 & 0.984 & 0.975 & \\
\hline & 1.232 & 1.040 & 1.031 & 1.023 & 1.014 & 1.005 & \\
\hline \multirow[t]{6}{*}{0.7295} & 0 & 0.827 & 0.818 & 0.810 & 0.801 & 0.792 & \\
\hline & 0.248 & 0.872 & 0.864 & 0.855 & 0.846 & n.a. & \\
\hline & 0.491 & 0.913 & 0.904 & 0.895 & 0.886 & 0.878 & \\
\hline & 0.739 & 0.949 & 0.940 & 0.931 & 0.921 & 0.912 & \\
\hline & 0.984 & 0.982 & 0.973 & 0.964 & 0.954 & 0.945 & \\
\hline & 1.231 & 1.011 & 1.002 & 0.993 & 0.984 & 0.974 & \\
\hline
\end{tabular}


Table 3: Results of the viscosity measurements: 1-propanol mole fraction of the INN-free solvent mixture $\hat{x}_{\mathrm{P}}$, overall INN molality $b_{\mathrm{INN}}$, temperature $T$, viscosity $\eta$. The pressure $p$ is $101.3 \mathrm{kPa}$. The standard uncertainties are $u\left(\hat{x}_{\mathrm{P}}\right)=0.0005 \mathrm{~mol} \mathrm{~mol}^{-1}$, $u\left(b_{\mathrm{INN}}\right)=0.005 \mathrm{~mol} \mathrm{~kg}^{-1}, u(T)=0.05 \mathrm{~K}$ and $u(p)=3 \mathrm{kPa}$. The relative standard uncertainties of the viscosity are given in the table. Data for pure water as the solvent from our previous work ${ }^{10}$ (rounded to match the number of decimals) are included here for convenience.

\begin{tabular}{|c|c|c|c|c|c|c|c|c|}
\hline \multirow{2}{*}{$\begin{array}{c}\hat{x}_{\mathrm{P}} \\
\mathrm{mol} \mathrm{mol}^{-1}\end{array}$} & \multirow{2}{*}{$\begin{array}{c}b_{\mathrm{INN}} \\
\mathrm{mol} \mathrm{kg}^{-1}\end{array}$} & \multicolumn{5}{|c|}{$\eta / \mathrm{mPa} \mathrm{s}$} & \multirow[t]{2}{*}{$u_{\mathrm{r}}(\eta)$} & \\
\hline & & $T=293.15 \mathrm{~K}$ & $303.15 \mathrm{~K}$ & $313.15 \mathrm{~K}$ & $323.15 \mathrm{~K}$ & $333.15 \mathrm{~K}$ & & \\
\hline \multirow[t]{5}{*}{0} & 0.248 & 1.19 & 0.94 & 0.79 & 0.71 & 0.57 & 0.07 & \multirow{5}{*}{10} \\
\hline & 0.495 & 1.41 & 1.13 & 0.94 & 0.78 & 0.69 & 0.07 & \\
\hline & 0.743 & 1.62 & 1.31 & 1.08 & 0.91 & 0.79 & 0.07 & \\
\hline & 0.990 & 1.86 & 1.49 & 1.23 & 1.03 & 0.89 & 0.07 & \\
\hline & 1.237 & 2.11 & 1.69 & 1.39 & 1.16 & 0.99 & 0.07 & \\
\hline \multirow[t]{6}{*}{0.0908} & 0 & 2.48 & 1.73 & 1.29 & 1.04 & 0.84 & 0.066 & \\
\hline & 0.246 & 2.76 & 1.99 & 1.50 & 1.18 & 0.97 & 0.066 & \\
\hline & 0.493 & 3.11 & 2.24 & 1.71 & 1.35 & 1.10 & 0.066 & \\
\hline & 0.739 & 3.42 & 2.52 & 1.93 & 1.54 & 1.27 & 0.066 & \\
\hline & 0.954 & 3.80 & 2.82 & 2.15 & 1.71 & 1.39 & 0.066 & \\
\hline & 1.231 & 4.23 & 3.11 & 2.41 & 1.91 & 1.56 & 0.066 & \\
\hline \multirow[t]{6}{*}{0.2306} & 0 & 3.17 & 2.25 & 1.66 & 1.30 & 1.04 & 0.061 & \\
\hline & 0.246 & 3.69 & 2.66 & 1.99 & 1.53 & 1.22 & 0.061 & \\
\hline & 0.499 & 4.29 & 3.11 & 2.34 & 1.82 & 1.44 & 0.061 & \\
\hline & 0.740 & 4.93 & 3.58 & 2.70 & 2.09 & 1.67 & 0.061 & \\
\hline & 0.982 & 5.62 & 4.09 & 3.08 & 2.39 & 1.91 & 0.061 & \\
\hline & 1.231 & 6.39 & 4.66 & 3.50 & 2.72 & 2.17 & 0.061 & this work \\
\hline \multirow[t]{6}{*}{0.4734} & 0 & 2.94 & 2.15 & 1.63 & 1.26 & 1.00 & 0.051 & \\
\hline & 0.247 & 3.82 & 2.80 & 2.11 & 1.63 & 1.30 & 0.051 & \\
\hline & 0.493 & 4.86 & 3.54 & 2.65 & 2.04 & 1.60 & 0.051 & \\
\hline & 0.738 & 6.02 & 4.35 & 3.24 & 2.47 & 1.93 & 0.051 & \\
\hline & 0.986 & 7.31 & 5.24 & 3.87 & 2.93 & 2.27 & 0.051 & \\
\hline & 1.232 & 8.67 & 6.16 & 4.52 & 3.40 & 2.62 & 0.051 & \\
\hline \multirow[t]{6}{*}{0.7295} & 0 & 2.52 & 1.92 & 1.49 & 1.18 & 0.95 & 0.041 & \\
\hline & 0.248 & 3.63 & 2.70 & 2.06 & 1.62 & n.a. & 0.041 & \\
\hline & 0.491 & 4.98 & 3.63 & 2.70 & 2.23 & 1.77 & 0.041 & \\
\hline & 0.739 & 6.65 & 4.74 & 3.47 & 2.60 & 2.04 & 0.041 & \\
\hline & 0.984 & 8.43 & 5.92 & 4.27 & 3.17 & 2.41 & 0.041 & \\
\hline & 1.231 & 10.32 & 7.13 & 5.10 & 3.74 & 2.82 & 0.041 & \\
\hline
\end{tabular}


Table 4: Results of the thermal conductivity measurements: 1-propanol mole fraction of the INN-free solvent mixture $\hat{x}_{\mathrm{P}}$, overall INN molality $b_{\mathrm{INN}}$, temperature $T$, thermal conductivity $\lambda$. The pressure $p$ is $101.3 \mathrm{kPa}$. The standard uncertainties are $u\left(\hat{x}_{\mathrm{P}}\right)=0.0005 \mathrm{~mol} \mathrm{~mol}^{-1}, u\left(b_{\mathrm{INN}}\right)=0.005 \mathrm{~mol} \mathrm{~kg}^{-1}, u(T)=0.2 \mathrm{~K}, \quad u_{\mathrm{r}}(\lambda)=0.035$ and $u(p)=3 \mathrm{kPa}$. Data for pure water as the solvent from our previous work ${ }^{10}$ (rounded to match the number of decimals) are included here for convenience.

\begin{tabular}{c|c|ccc|c}
\hline \hline $\begin{array}{c}\hat{x}_{\mathrm{P}} \\
\mathrm{mol} \mathrm{mol}^{-1}\end{array}$ & $\begin{array}{c}b_{\text {INN }} \\
\mathrm{mol} \mathrm{kg}^{-1}\end{array}$ & $T=288.15 \mathrm{~K}^{2}$ & $298.15 \mathrm{~K}$ & $308.15 \mathrm{~K}$ & \\
\hline 0 & 0 & 598 & 612 & 633 & \\
& 0.252 & 510 & 545 & 564 & \multirow{2}{*}{10} \\
& 0.497 & 472 & 519 & 545 & \\
& 0.754 & 507 & 532 & 556 & \\
& 1.004 & 498 & 525 & 547 & \\
\hline 0.0908 & 0 & 436 & 439 & 446 & \\
0.2306 & 0 & 297 & 298 & 304 & \\
& 0.254 & 260 & 288 & 304 & \\
& 0.501 & 235 & 266 & 285 & \\
& 0.748 & 260 & 286 & 293 & \\
& 0.996 & 258 & 279 & 277 & this work \\
0.4734 & 0 & 209 & 207 & 208 & \\
0.7295 & 0 & 172 & 170 & 169 & \\
& 0.249 & 150 & 155 & 156 & \\
& 0.498 & 137 & 148 & 152 & \\
& 0.749 & 142 & 150 & 154 & \\
& 0.998 & 164 & 168 & 170 & \\
\hline \hline
\end{tabular}


Table 5: Results of the heat capacity measurements: 1-propanol mole fraction of the INN-free solvent mixture $\hat{x}_{\mathrm{P}}$, overall $\mathrm{INN}$ molality $b_{\mathrm{INN}}$, temperature $T$, heat capacity $c_{\mathrm{p}}$. The pressure $p$ is $101.3 \mathrm{kPa}$. The standard uncertainties are $u\left(\hat{x}_{\mathrm{P}}\right)=0.0005 \mathrm{~mol} \mathrm{~mol}^{-1}, u\left(b_{\mathrm{INN}}\right)=0.005 \mathrm{~mol} \mathrm{~kg}^{-1}, u(T)=0.2 \mathrm{~K}, u_{\mathrm{r}}\left(c_{\mathrm{p}}\right)=0.04$ and $u(p)=3 \mathrm{kPa}$. Data for pure water as the solvent from our previous work ${ }^{10}$ are included here for convenience.

\begin{tabular}{c|c|ccc|c}
\hline \hline $\begin{array}{c}\hat{x}_{\mathrm{P}} \\
\mathrm{mol} \mathrm{mol}^{-1}\end{array}$ & $\begin{array}{c}b_{\mathrm{INN}} \\
\mathrm{mol} \mathrm{kg}^{-1}\end{array}$ & $\begin{array}{c}\mid c \\
c_{\mathrm{p}} / \mathrm{J} \mathrm{mol}^{-1} \mathrm{~K}^{-1}\end{array}$ & & \\
\hline 0 & 0 & 75.8 & 75.6 & 75.8 & \\
& 0.252 & 71.6 & 72.2 & 72.9 & \multirow{1}{*}{10} \\
& 0.497 & 72.1 & 73.6 & 74.3 & \\
& 0.754 & 70.9 & 71.0 & 72.7 & \\
& 1.004 & 70.4 & 71.1 & 73.6 & \\
\hline 0.0908 & 0 & 87.7 & 90.0 & 92.5 & \\
0.2306 & 0 & 92.9 & 95.6 & 99.4 & \\
& 0.254 & 80.6 & 90.9 & 98.5 & \\
& 0.501 & 77.5 & 89.3 & 97.9 & \\
& 0.748 & 88.9 & 99.9 & 105.1 & \\
& 0.996 & 92.6 & 102.5 & 104.9 & this work \\
0.4734 & 0 & 106.6 & 109.0 & 112.4 & \\
0.7295 & 0 & 123.7 & 126.1 & 129.0 & \\
& 0.249 & 106.1 & 113.5 & 118.2 & \\
& 0.498 & 99.8 & 111.7 & 119.2 & \\
& 0.749 & 107.8 & 117.9 & 125.4 & \\
& 0.998 & 130.3 & 138.7 & 145.5 & \\
\hline \hline
\end{tabular}


Table 6: Parameters of the correlations for the pure component properties of 1propanol and water, cf. Eq. (5). Parameters for water were taken from our previous work $^{10}$ and are repeated here for convenience.

\begin{tabular}{|c|c|c|c|c|}
\hline Property & Component & $a$ & $b$ & $c$ \\
\hline Molar volume & 1-propanol & $6.7546 \cdot 10^{1}$ & $-2.4736 \cdot 10^{-2}$ & $1.6835 \cdot 10^{-4}$ \\
\hline$v / \mathrm{cm}^{3} \mathrm{~mol}^{-1}$ & water & $2.3432 \cdot 10^{1}$ & $-4.0429 \cdot 10^{-2}$ & $7.5233 \cdot 10^{-5}$ \\
\hline Viscosity & 1-propanol & $4.2790 \cdot 10^{1}$ & $-2.3258 \cdot 10^{-1}$ & $3.2034 \cdot 10^{-4}$ \\
\hline$\eta / \mathrm{mPa} \mathrm{s}$ & water & $2.1979 \cdot 10^{1}$ & $-1.2303 \cdot 10^{-1}$ & $1.7550 \cdot 10^{-4}$ \\
\hline Thermal conductivity & 1-propanol & $1.9456 \cdot 10^{2}$ & $-1.4997 \cdot 10^{-1}$ & - \\
\hline$\lambda / \mathrm{mW} \mathrm{m}^{-1} \mathrm{~K}^{-1}$ & water & $1.0047 \cdot 10^{2}$ & $1.7235 \cdot 10^{0}$ & - \\
\hline Isobaric heat capacity & 1-propanol & $4.6391 \cdot 10^{1}$ & $3.1959 \cdot 10^{-1}$ & - \\
\hline$c_{\mathrm{p}} / \mathrm{J} \mathrm{mol}^{-1} \mathrm{~K}^{-1}$ & water & $7.5733 \cdot 10^{1}$ & - & - \\
\hline
\end{tabular}


Table 7: Parameters of the Redlich-Kister correlations for the molar volume, viscosity, thermal conductivity and isobaric heat capacity, cf. Eqs. (6) - (7).

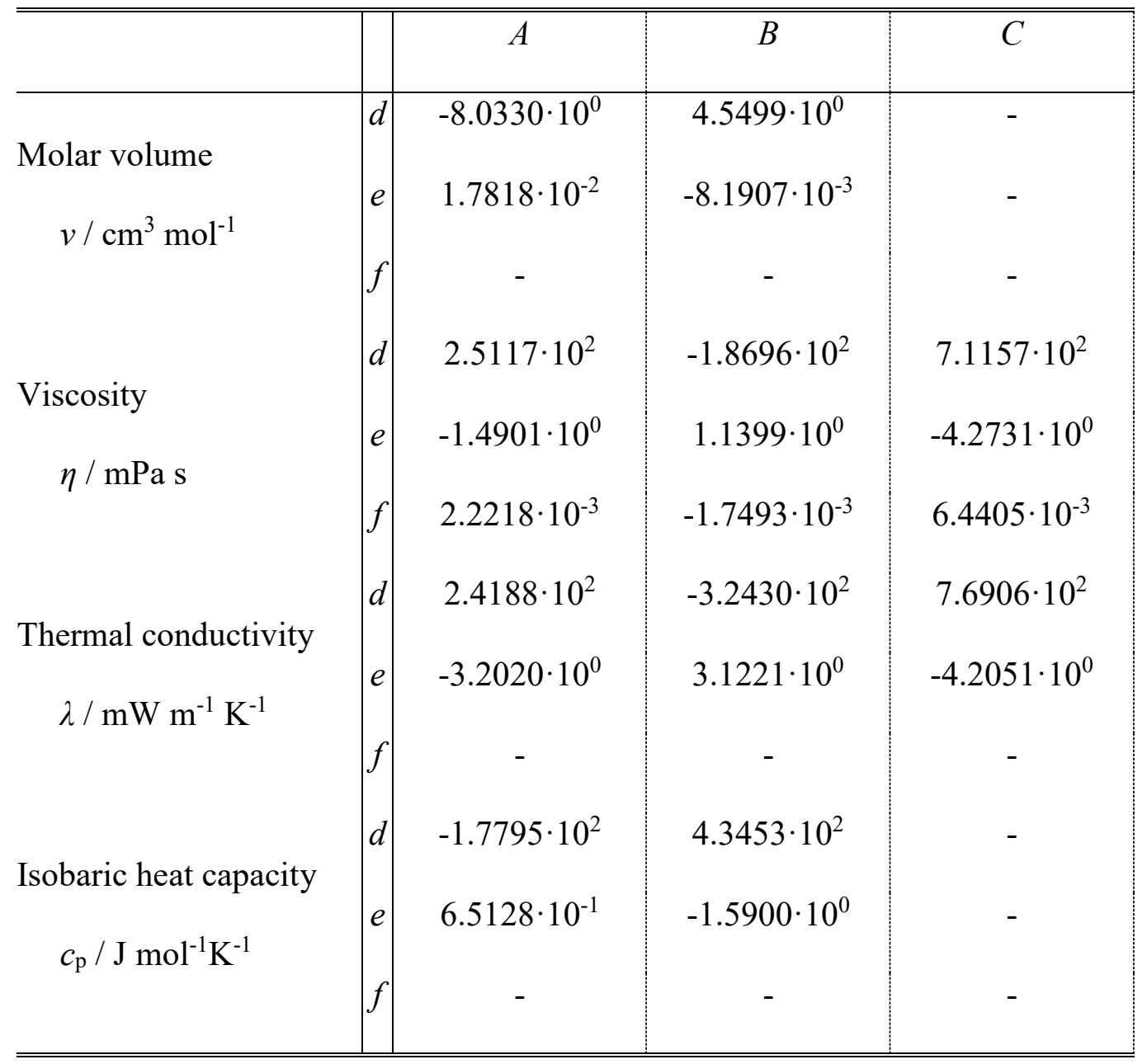


Table 8: Parameters of the correlations for the description of the influence of INN on the molar volume, viscosity, thermal conductivity and isobaric heat capacity, cf. Eq. (8) - (9).

\begin{tabular}{|c|c|c|c|c|c|c|c|c|c|}
\hline & & $\bar{D}$ & $\bar{E}$ & $\overline{F F}$ & 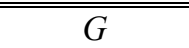 & $\overline{\mathrm{H}}$ & $\overline{I I}$ & 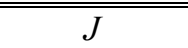 & $\bar{K}$ \\
\hline Molar volume & $g$ & $1.5105 \cdot 10^{2}$ & $4.5313 \cdot 10^{2}$ & $-5.6027 \cdot 10^{2}$ & $-1.1598 \cdot 10^{2}$ & $1.2457 \cdot 10^{1}$ & $-5.8882 \cdot 10^{3}$ & $8.2382 \cdot 10^{3}$ & $1.7775 \cdot 10^{2}$ \\
\hline$v / \mathrm{cm}^{3} \mathrm{~mol}^{-1}$ & $h$ & $1.7126 \cdot 10^{-1}$ & $-1.6254 \cdot 10^{0}$ & $2.0547 \cdot 10^{0}$ & $-2.3547 \cdot 10^{-1}$ & $4.7260 \cdot 10^{-1}$ & $1.4842 \cdot 10^{1}$ & $-1.7016 \cdot 10^{1}$ & $-3.3866 \cdot 10^{0}$ \\
\hline Viscosity & $g$ & $2.9017 \cdot 10^{1}$ & $3.2206 \cdot 10^{3}$ & $-7.1772 \cdot 10^{3}$ & $3.9826 \cdot 10^{3}$ & $1.0185 \cdot 10^{4}$ & $-6.2853 \cdot 10^{4}$ & $1.6105 \cdot 10^{5}$ & $-9.8667 \cdot 10^{4}$ \\
\hline$\eta / \mathrm{mPa} \mathrm{s}$ & $h$ & $1.8530 \cdot 10^{-2}$ & $-1.0015 \cdot 10^{1}$ & $2.2402 \cdot 10^{1}$ & $-1.2528 \cdot 10^{1}$ & $-3.2591 \cdot 10^{1}$ & $2.1032 \cdot 10^{2}$ & $-5.2801 \cdot 10^{2}$ & $3.2157 \cdot 10^{2}$ \\
\hline Thermal conductivity & $g$ & $-8.8523 \cdot 10^{4}$ & $1.2726 \cdot 10^{5}$ & $-3.9655 \cdot 10^{4}$ & - & $4.2299 \cdot 10^{6}$ & $-1.2208 \cdot 10^{7}$ & $9.3620 \cdot 10^{6}$ & - \\
\hline$\lambda / \mathrm{mW} \mathrm{m}^{-1} \mathrm{~K}^{-1}$ & $h$ & $2.3937 \cdot 10^{2}$ & $-1.2272 \cdot 10^{2}$ & $-1.8827 \cdot 10^{2}$ & - & $-1.1801 \cdot 10^{4}$ & $2.7577 \cdot 10^{4}$ & $-1.7294 \cdot 10^{4}$ & - \\
\hline Isobaric heat capacity & $g$ & $-4.5294 \cdot 10^{3}$ & $-5.6751 \cdot 10^{4}$ & $5.8485 \cdot 10^{4}$ & - & $7.9355 \cdot 10^{4}$ & $1.4611 \cdot 10^{6}$ & $-1.6738 \cdot 10^{6}$ & - \\
\hline$c_{\mathrm{p}} / \mathrm{J} \mathrm{mol}^{-1} \mathrm{~K}^{-1}$ & $h$ & $1.3733 \cdot 10^{1}$ & $1.8268 \cdot 10^{2}$ & $-1.9381 \cdot 10^{2}$ & - & $-2.2600 \cdot 10^{2}$ & $-4.4344 \cdot 10^{3}$ & $5.1880 \cdot 10^{3}$ & - \\
\hline
\end{tabular}




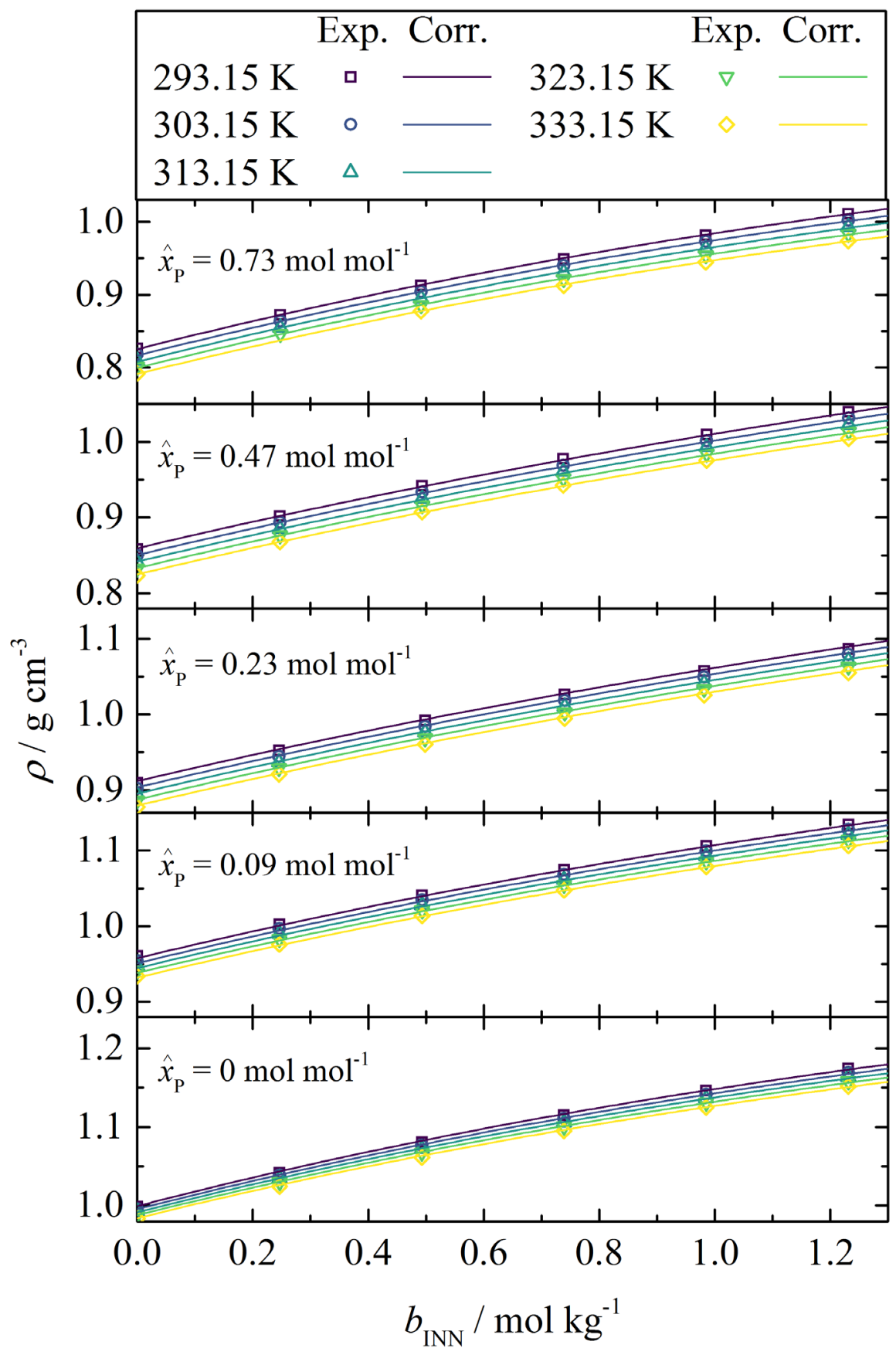

Figure 1: Densities $\rho$ of solutions of INN + 1-propanol + water at $101.3 \mathrm{kPa}$. Symbols $(\square 293.15 \mathrm{~K}, \circ 303.15 \mathrm{~K}, \triangle 313.15 \mathrm{~K}, \nabla 323.15 \mathrm{~K}, \quad 333.15 \mathrm{~K})$ are experimental results. Experimental uncertainties are always within symbol size. Lines $(-293.15 \mathrm{~K},-303.15 \mathrm{~K},-313.15 \mathrm{~K},-323.15 \mathrm{~K},-333.15 \mathrm{~K})$ are empirical correlations, cf. Eqs. (1) - (11), with parameters listed in Tables 6 - 8. 


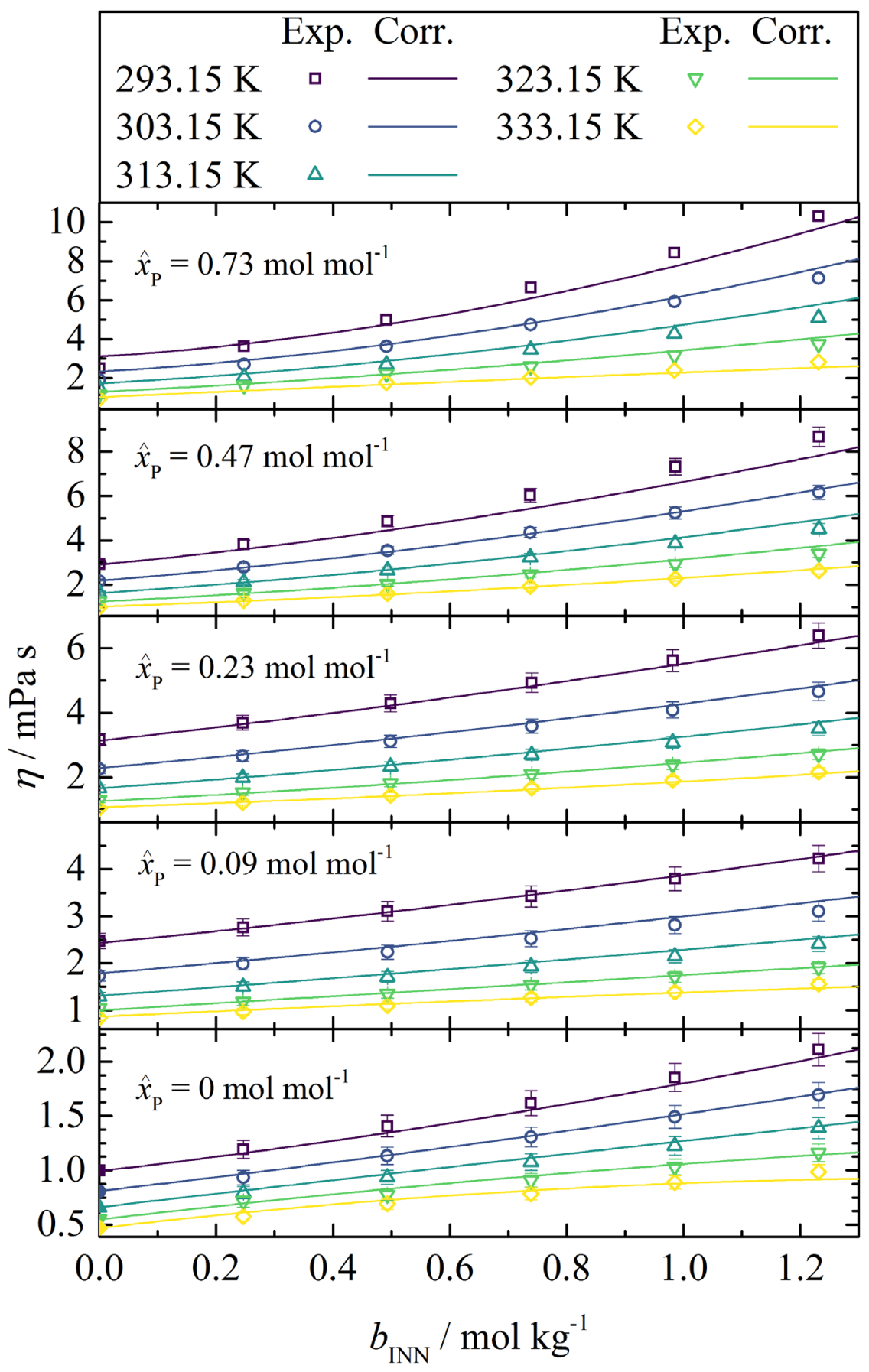

Figure 2: Viscosities $\eta$ of solutions of INN +1 -propanol + water at $101.3 \mathrm{kPa}$. Open symbols ( $\square 293.15 \mathrm{~K}, \circ 303.15 \mathrm{~K}, \triangle 313.15 \mathrm{~K}, \nabla 323.15 \mathrm{~K}, \quad 333.15 \mathrm{~K})$ are experimental results. Error bars indicate the experimental standard uncertainty. Lines $(-293.15 \mathrm{~K},-303.15 \mathrm{~K},-313.15 \mathrm{~K},-323.15 \mathrm{~K},-333.15 \mathrm{~K})$ are empirical correlations, cf. Eqs. (1) - (11), with parameters listed in Tables 6 - 8. Solid symbols 
$(\backsim 293.15 \mathrm{~K}, \bullet 303.15 \mathrm{~K}, \Delta 313.15 \mathrm{~K}, \nabla 323.15 \mathrm{~K}, 333.15 \mathrm{~K})$ at $b_{\mathrm{INN}}=0 \mathrm{~mol} \mathrm{~kg}^{-1}$, $\hat{x}_{\mathrm{P}}=0 \mathrm{~mol} \mathrm{~mol}^{-1}$ are experimental data taken from the literature ${ }^{29}$. 


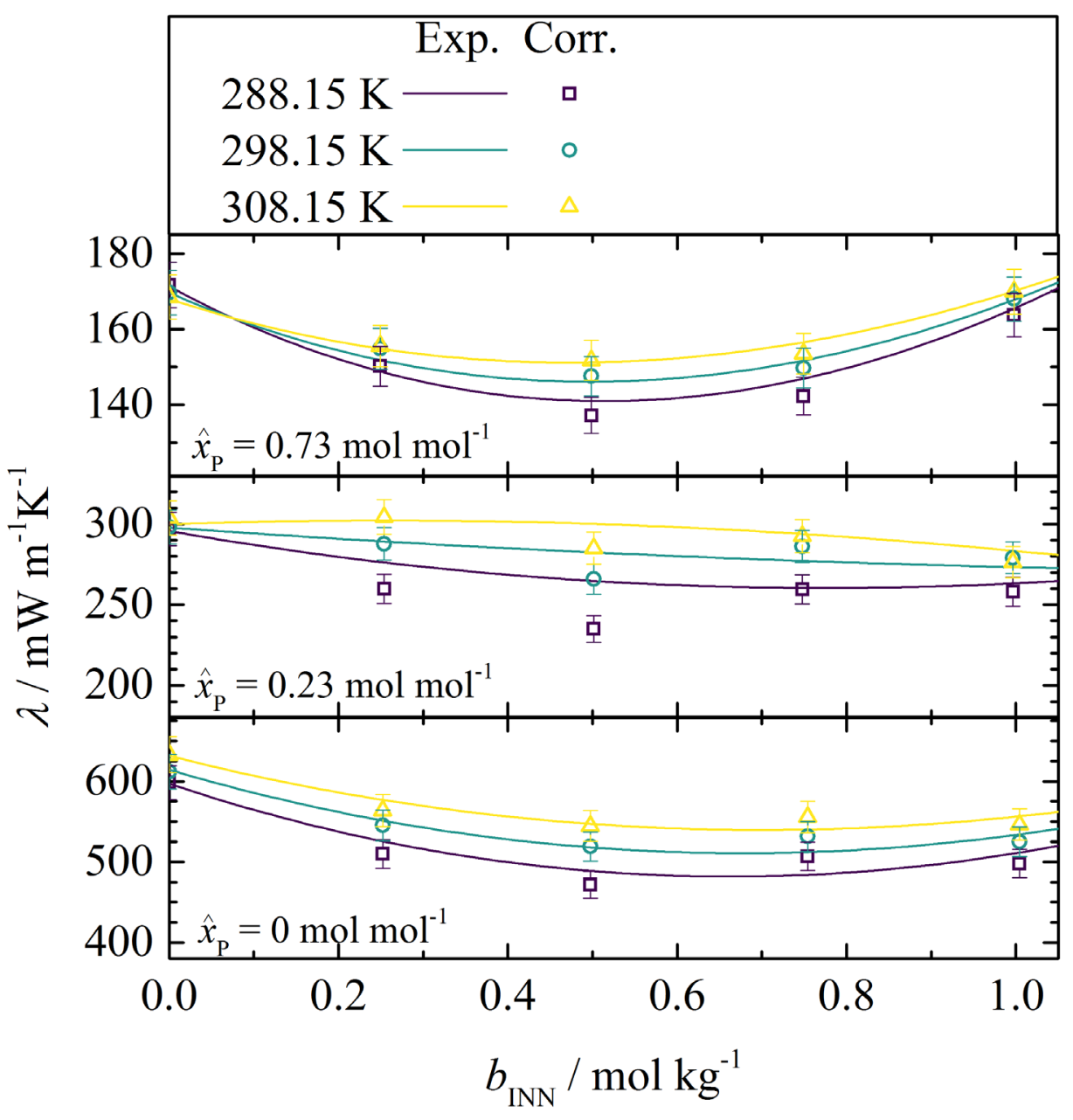

Figure 3: Thermal conductivities $\lambda$ of solutions of INN +1 -propanol + water at $101.3 \mathrm{kPa}$. Symbols ( $\square 288.15 \mathrm{~K}, \circ 298.15 \mathrm{~K}, \triangle 308.15 \mathrm{~K})$ are experimental results. Error bars indicate the experimental standard uncertainty. Lines ( $-288.15 \mathrm{~K}$, - 298.15 K, - 308.15 K) are empirical correlations, cf. Eqs. (1) - (11), with parameters listed in Tables $6-8$. 


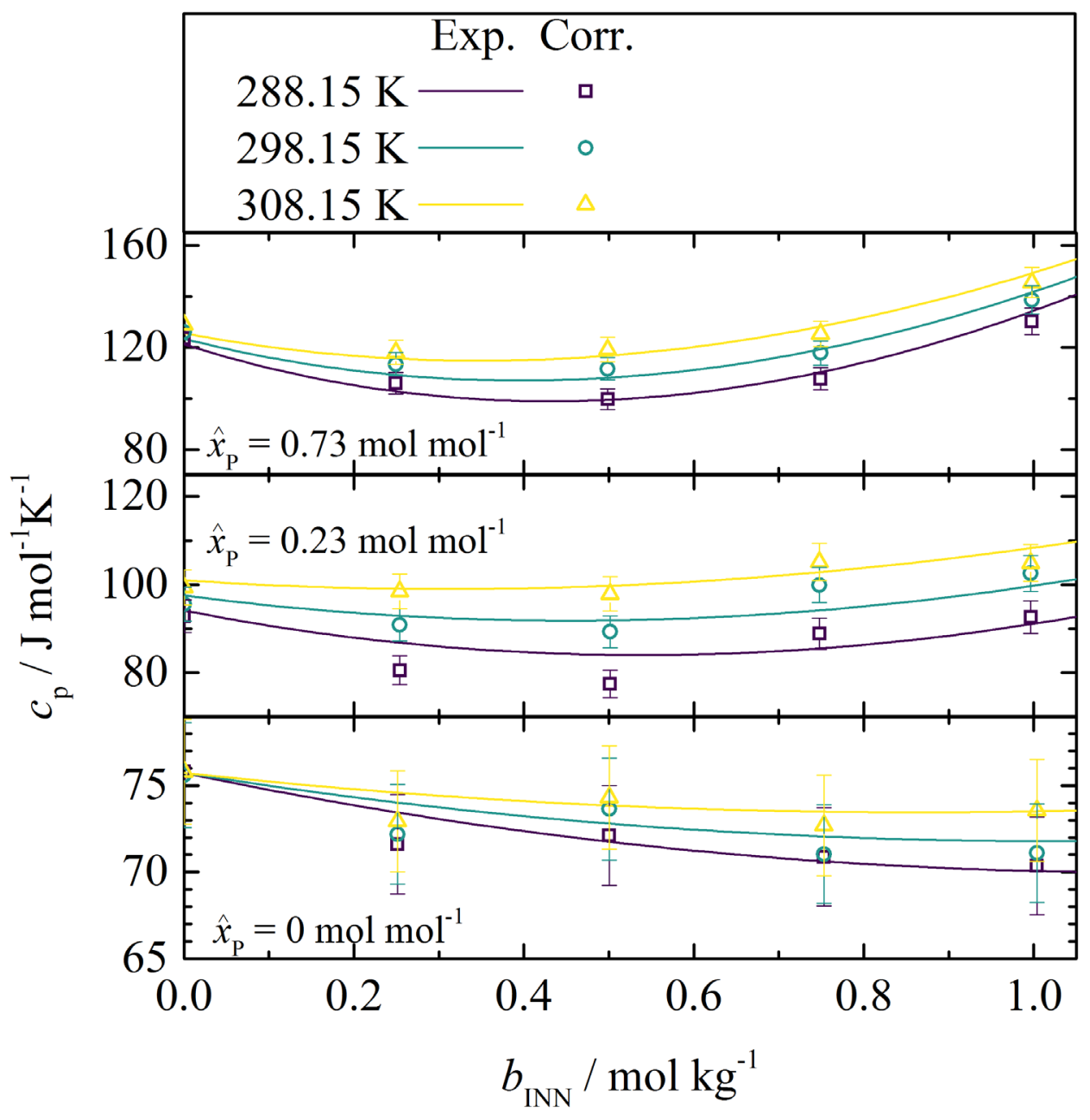

Figure 4: Isobaric heat capacities $c_{\mathrm{p}}$ of solutions of INN +1 -propanol + water at $101.3 \mathrm{kPa}$. Symbols ( $\square 288.15 \mathrm{~K}, \circ 298.15 \mathrm{~K}, \triangle 308.15 \mathrm{~K})$ are experimental results. Error bars indicate the experimental standard uncertainty. Lines ( $288.15 \mathrm{~K}$, - $298.15 \mathrm{~K},-308.15 \mathrm{~K})$ are empirical correlations, cf. Eqs. (1) - (11), with parameters listed in Tables $6-8$. 


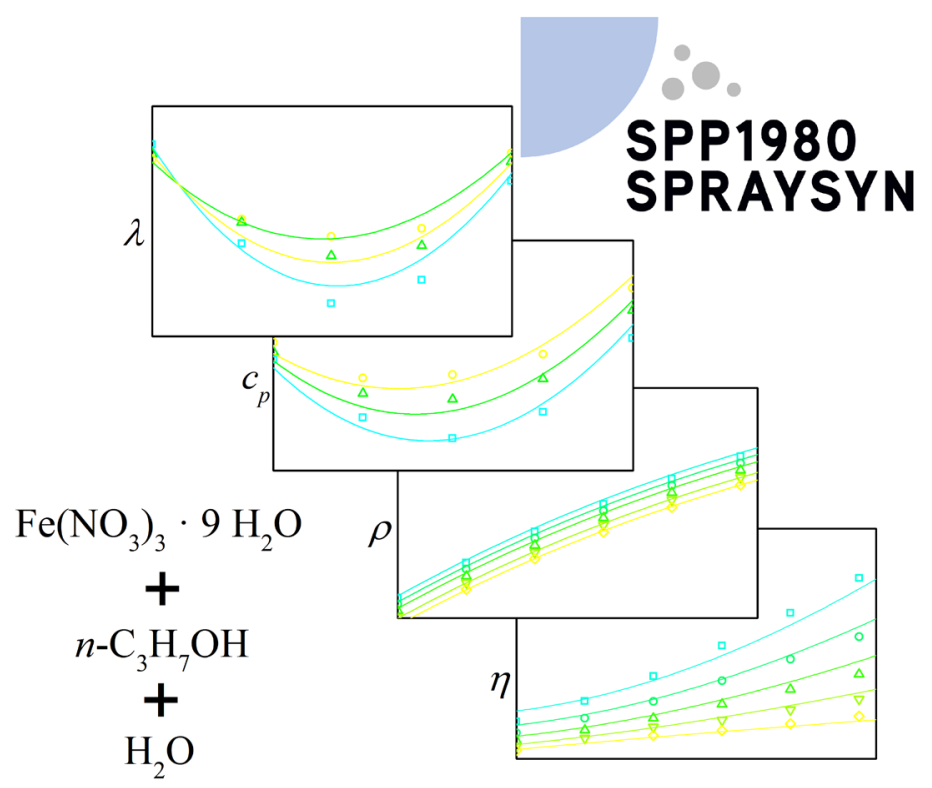

TOC Graphic: For Table of Contents Only 